\title{
Chapter 1 \\ Introduction to Scheduling in Industry 4.0 and Cloud Manufacturing Systems
}

\author{
Dmitry Ivanov, Boris Sokolov, and Alexandre Dolgui
}

\begin{abstract}
In this chapter, we present an introduction to scheduling in Industry 4.0 and cloud manufacturing systems. We elaborate on the peculiarities of scheduling and sequencing problems in the context of Industry 4.0 and smart manufacturing. We delineate recent research streams and summarize the structure and contribution of the book.
\end{abstract}

\subsection{Scope of the Research Domain}

Cloud manufacturing and Industry 4.0 emerge with specific scheduling problems encompassing complex hybrid logical and terminal constraints, non-stationarity in process execution, as well as complex interrelations between dynamics in process design, capacity utilization, and machine setups (Ivanov et al. 2020). The flexibility and service orientation of digital manufacturing allow for dynamically changing process technologies (i.e., flexibly reconfigurable jobs through customer-specific sequencing of operations) to achieve the product individualization and variety. The Industry 4.0 technology and cloud manufacturing are enabling flexible production, particularly through the use of cyber-physical systems and highly customized assemblies (Hwang et al. 2017; Ahn et al. 2019; Frazzon et al. 2018; Leusin et al. 2018; Tao et al. 2018; Panetto et al. 2019; Yang et al. (2019)) in order to deliver

D. Ivanov $(\bowtie)$

Berlin School of Economics and Law, Berlin, Germany

e-mail: divanov@hwr-berlin.de

B. Sokolov

Saint Petersburg Institute for Informatics and Automation of the RAS (SPIIRAS), St. Petersburg, Russia

e-mail: sokol@iias.spb.su

\author{
A. Dolgui \\ IMT Atlantique, LS2N—CNRS, La Chantrerie, Nantes, France \\ e-mail: alexandre.dolgui@imt-atlantique.fr
}


manufacturing services on-demand (Ivanov et al. 2018; Ahn et al. 2019; Liu et al. 2019; Dolgui et al. 2019b; Fragapane et al. 2020; Shukla et al. 2019; Zhou et al. 2018).

Such innovative production strategies engender new challenges and opportunities for short-term job scheduling and sequencing. One difficulty is the strong coupling when product and process are created simultaneously (Kusiak 2018). Simultaneous product and process creation direct the discussion in a class of scheduling problems that have mixed structural-temporal-logical constraints with order scheduling based on a search for free resources for free operations (Dolgui et al. 2019a). Another peculiarity of scheduling in cloud manufacturing and Industry 4.0 is its datadriven nature that, at the same time, becomes favorable for development of new decomposition methods.

Notably, the cloud manufacturing and Industry 4.0 build upon a service paradigm. Flexible processes and flexible machines allow to create a principally new entity for scheduling, that is, a service-an entity needed to fulfill a process step in a technological chain. The services are formed dynamically based on the available machines and operations. The services can be built by almost any combination of machines and operations (Ivanov et al. 2016; Ahn et al. 2019; Liu et al. 2019). As such, in digital manufacturing, the process design and job scheduling are integrated due to the flexible usage of services instead of the rigid and fixed allocations of operations and machines. In this context, the focus of scheduling shifts from assigning jobs to machines but rather emerges with a combination of process (task) composition and service composition, which are performed simultaneously to deliver manufacturing services to consumers on-demand.

Moreover, the COVID-19 outbreak - the unprecedented challenge to manufacturing industry - has clearly shown and highlighted the importance of scheduling in Industry 4.0 and cloud manufacturing. Firms with established technologies for manufacturing visibility and digital control were able to react to disruptions more flexible and responsive (Choi et al. 2020; Ivanov 2020; Ivanov and Dolgui 2020; Ivanov and Das 2020). Ni et al. (2020) point to the need of to develop "predictive models for proactive scheduling and dynamic planning of supply demands with the consideration of uncertainties and risk factors. These predictive models will help corporate decision-makers do what-if analysis of various scenarios".

In summary, the existing knowledge on scheduling in Industry 4.0, smart manufacturing, and cloud manufacturing is scattered over different methodologies but most of them share a certain set of attributes such as (a) flexible process design, (b) communication of products and machines, (c) flexible machines, and (d) serviceoriented manufacturing.

For example, Audi smart factory in Baden-Württemberg implements a highly flexible assembly system based on the use of automated guided vehicles. Contrary to the traditional assembly systems with fixed layouts and process designs, the Audi smart factory allows for highly flexible process design and sequencing of production orders in order to achieve the highest degree of the product individualization while maintaining the manufacturing efficiency (Audi 2019). MindSphere (a manufacturing platform of Siemens) is cloud-based and represented an open Internetof-Things (IoT) operating system where products, plants, systems, and machines are 
connected with each other to enable the usage of data generated by the IoT with advanced analytics in schedule optimization (Siemens 2019). Another flexibility driver are autonomous mobile robots that make it possible to develop principally new forms of assembly by flexible reallocation of the manufacturing services needed to produce a product (Nielsen et al. 2017; Fragapane et al. 2020). With the help of smart sensors and plug-and-produce cyber-physical systems, the stations in the assembly system are capable of changing the operation processing and setup sequences according to the actual order of the incoming flows and capacity utilization (Theorin et al. 2017). In the FOUP-front opening unified pods-technology in the semiconductor industry, robots are used for a real-time operation sequencing. Robots read the information about the products from the sensors and tags and decide flexibly, where to forward a wafer batch next (Mönch et al. 2012).

Despite the notable progress, scheduling in Industry 4.0 and cloud manufacturing is still at the beginning of its investigation. The results from the hybrid shop scheduling and sequencing with alternative parallel machines, resource constrained project scheduling with alternative chains, and design of reconfigurable manufacturing system and scheduling with both terminal and logical constraints can now be integrated into a unified framework of Industry 4.0 and require an extension toward models with hybrid structural-terminal-logical constraints (Dolgui et al. 2019a).

In the first published paper on scheduling in Industry 4.0, Ivanov et al. (2016) underline the role of real-time information to reduce combinatorial complexity of the NP-hard scheduling problems. Moreover, this study depicted the resemblance of Industry 4.0-based manufacturing systems to flexible multiprocessor flow shops. Rossit et al. (2019) developed a concept of smart scheduling, aiming to yield flexible and efficient production schedules that are formed dynamically in an event-oriented matter. Echoing the results in Ivanov et al. (2016), they also referred to similarity of the smart scheduling to flow shop scheduling problems. In Xu et al. (2019), online algorithms were developed to maximize the capacity of the machines in custom manufacturing environment with IoT (Internet-of-Things) capability. Despite some reported advances, doubts have been raised and considerable ambiguity remains, however, as to if and how the increased complexity of scheduling problems in the digital manufacturing can be efficiently tackled by the existing optimization techniques. Other recent advances in scheduling in cloud manufacturing have been documented for both products (Mourtzis and Vlachou 2018; Vespoli et al. 2019; Vahedi-Nouri et al. 2019; Ding et al. 2019; Helo et al. 2019; Yuan et al. 2019) and services (Chen et al. 2019) and reviewed by Liu et al. (2019) and Zhang et al. (2019).

\subsection{Structure of the Book}

This book has resulted from the activities of International Federation of Automatic Control Technical Committee (IFAC TC) 5.2 "Manufacturing Modelling for Management and Control." The book offers an introduction and advanced techniques of scheduling applications to cloud manufacturing and Industry 4.0 systems for larger 
audience. This book uncovers fundamental principles and recent developments in the theory and application of scheduling methodology to cloud manufacturing and Industry 4.0.

The purpose of this book is to comprehensively present recent developments in scheduling in cloud manufacturing and Industry 4.0 and to systemize these developments in new taxonomies and methodological principles to shape this new research domain. This book addresses the needs of both researchers and practitioners to uncover the challenges and opportunities of scheduling techniques' applications to cloud manufacturing and Industry 4.0. For the first time, it comprehensively conceptualizes scheduling in cloud manufacturing and Industry 4.0 systems as a new research domain. The chapters of the book are written by the leading international experts and utilize methods of operations research, industrial engineering, and computer science. Such a multidisciplinary combination is unique and comprehensively deciphers major problem taxonomies, methodologies, and applications to scheduling in cloud manufacturing and Industry 4.0.

Distinctive features of this book:

- Uncovering fundamental principles and recent developments in the theory and application of scheduling methodology to cloud manufacturing and Industry 4.0.

- Bridging the scheduling theory to cloud manufacturing and Industry 4.0 systems.

- Systemizing new developments and deciphering taxonomies and methodological principles to shape the new research domain scheduling in cloud manufacturing and Industry 4.0 systems.

- Innovative applications of scheduling in cloud manufacturing and Industry 4.0.

- Consideration of models with only terminal constraints, with hybrid terminallogical constraints, and with hybrid structural-terminal-logical constraints.

- Analysis of computational algorithms.

- Data-driven scheduling models and analytics.

- Unique multidisciplinary view with utilization of operations research, industrial engineering, and computer science techniques.

The book contains 13 chapters written by the leading researchers in the field across the globe.

In the Introductory chapter "Introduction to Scheduling in Industry 4.0 and Cloud Manufacturing Systems," the book editors Dmitry Ivanov, Boris Sokolov, and Alexandre Dolgui elaborate on the peculiarities of scheduling and sequencing problems in the setting of Industry 4.0 and smart manufacturing. They delineate recent research streams and summarize the structure and contribution of the book.

Real-Time Control Dmitry Ivanov, Boris Sokolov, Frank Werner, and Alexandre Dolgui develop in their chapter, "Proactive Scheduling and Reactive Real-Time Control in Industry 4.0," a control-theoretic perspective of modeling highly flexible manufacturing systems when process and schedule need to be created simultaneously. By combining the advantages of continuous and discrete optimization, their chapter develops a decomposition method for shop floor scheduling in Industry 4.0 manufacturing systems. 
Digital Twin Ícaro Agostino, Sousa Romolo, Eike Broda, Enzo M. Frazzon, and Michael Freitag focus their chapter, "Using a Digital-Twin for Production Planning and Control in Industry 4.0," on the application of simulation models in production and logistic systems to frame the digital twins. A digital-twin approach to production planning and control using current cyber-physical systems state data in real time is presented and validated.

Cloud Material Handling System Fabio Sgarbossa, Mirco Peron, and Giuseppe Fragapane propose in their chapter, "Cloud Material Handling Systems: Conceptual Model and Cloud-Based Scheduling of Handling Activities," a new material handling paradigm called Cloud Material Handling System (CMHS), developed in the Logistics 4.0 Lab at Norwegian University of Science and Technology (NTNU), Norway. With the help of CMHS, scheduling of the Material Handling Modules can be optimized, increasing the flexibility and productivity of the overall manufacturing system.

Adaptation Dimitris Mourtzis describes in his chapter, "Adaptive Scheduling in the Era of Cloud Manufacturing," the evolution of scheduling techniques during the last decade. The chapter also provides insightful and meaningful inferences from the application of innovative solutions in industrial use cases.

Robust Scheduling Pascale Marangé, David Lemoine, Alexis Aubry, Sara Himmiche, Sylvie Norre, Christelle Bloch, and Jean-François Pétin present in their chapter, "Coupling Robust Optimization and Model-Checking Techniques for Robust Scheduling in the Context of Industry 4.0," a generic methodology for robustness analysis in production systems of Industry 4.0. The authors consider this as the first milestone for coupling Operations Research models for robust optimization and Discrete Event Systems models and tools for property checking for converging toward a solution with the required robustness level defined by the decision-makers.

Information Services Dmitry Ivanov and Boris Sokolov elaborate in their chapter, "Integrated Scheduling of Information Services and Logistics Flows in the Omnichannel System," on an integration of information services and logistics flows in the scheduling of omnichannel systems. The proposed service-oriented description makes it possible to coordinate the information services and material process schedules simultaneously. It also becomes possible to optimize the use of information services needed for physical supply processes. In addition, impact of disruptions in information services on the schedule execution in the physical structure is analyzed.

Human Factors Daria Battini, Serena Finco, and Fabio Sgarbossa contribute a chapter entitled "Human-Oriented Assembly Line Balancing and Sequencing Model in the Industry 4.0 Era." Using real-time monitoring approach, a dynamic scheduling and sequencing method is proposed to guarantee the right safety level for each worker. The authors provide a general overview of smart tools for measuring and quantifying the ergonomics level. Based on the data from smartwatches, they frame 
a multi-objective assembly line balancing model and an ergo-sequencing model demonstrating the benefits of using smart solutions and Industry 4.0 tools.

Modularity Nathalie Klement and Cristóvão Silva propose in their chapter, "A Generic Decision Support Tool to Planning and Assignment Problems: Industrial Applications and Industry 4.0," a generic, modular decision support tool to support decision-making in planning, assignment, scheduling, and lot-sizing in Industry 4.0 systems. They show applications of their approach to several tactical and operational problems, for example, a problem of planning activities with resources assignment for hospital systems, a lot-sizing and scheduling problem taking into account the setup time for a textile application and for a plastic injection problem, and a scheduling problem with precedence constraints. At the strategic level, this tool can also be used as part of the Industry 4.0 to design reconfigurable manufacturing systems.

Cloud Paradigm Andrea Grassi, Guido Guizzi, Liberatina Carmela Santillo, and Silvestro Vespoli analyze in their chapter, "The Manufacturing Planning and Control System: A Journey Toward the New Perspectives in Industry 4.0 Architectures," an evolution of manufacturing planning and control toward Industry 4.0 and cloud manufacturing paradigms. They present different classical approaches and extend their scope of application toward the positioning of Industry 4.0 in future market scenarios. Further, the authors elaborate on the new technologies in Industry 4.0, and how they can act as enablers for bridging the gap between current and future production control approaches. Finally, they explore the state of the art of Industry 4.0 and cloud manufacturing architectural implementations, also outlining further development possibilities and strategies.

Energy Efficiency Junheng Cheng, Feng Chu, and Peng Wu elaborate in their chapter, "Multi-Criteria Single Batch Machine Scheduling Under Time-of-Use Tariffs," on the sustainability issues and energy-efficient manufacturing in Industry 4.0. They introduce a basic single machine batch scheduling problem under time-ofuse (ToU) electricity tariffs. Then it is extended by further considering machine on/off switching. Finally, a single machine batch scheduling problem under ToU tariffs in a continuous-processing environment is investigated. For the three considered problems, appropriate mathematical models are established, and their problem properties and complexities are demonstrated.

Service Composition Haifeng Zhang, Yongkui Liu, Huagang Liang, Lihui Wang, and Lin Zhang devote their chapter, "Service Composition in Cloud Manufacturing: A DQN-Based Approach," to the application of deep reinforcement learning to solving cloud manufacturing service composition problems. They propose a deep Q network (DQN)-based service composition approach in which the system can learn how to find optimal service composition solutions automatically.

Rescheduling Daniel Alejandro Rossit, Fernando Tohmé, and Gonzalo Mejía introduce in their chapter, "The Tolerance Scheduling Problem in a Single Machine Case," a Tolerance Scheduling problem, which involves the decision-making issues in rescheduling processes. The solutions to this problem can be incorporated in the 
design of Decision Support Systems (DSS) in Industry 4.0 environments. The authors present the mathematical foundations for the solutions of the Tolerance Scheduling problem as well as the technical requirements of their embodiment in Industry 4.0's DSS.

\section{References}

Ahn, G., Park, Y.-J., \& Hur, S. (2019). Performance computation methods for composition of tasks with multiple patterns in cloud manufacturing. International Journal of Production Research, 57(2), 517-530.

Audi (2019). Flexible Montage in der Fahrzeugproduktion Die flexible Audi R8-Manufaktur mit fahrerlosen Transportfahrzeugen. Retrieved October 4, 2019 from https://www.plattformi40.de/PI40/Redaktion/DE/Anwendungsbeispiele/137-wandelbare-r8-manufaktur/beitragwandelbare-r8-manufaktur.html.

Chen, J., Huang, G. Q., Wang, J.-Q., \& Yang, C. (2019). A cooperative approach to service booking and scheduling in cloud manufacturing. European Journal of Operational Research, 273(3), 861-873.

Choi TY, Rogers D, Vakil B. (2020). Coronavirus is a wake-up call for supply chain management. Harvard business review, march 27th.

Ding, K., Chan, F. T. S., Zhang, X., Zhou, G., \& Zhang, F. (2019). Defining a Digital Twinbased Cyber-Physical Production System for autonomous manufacturing in smart shop floors. International Journal of Production Research, 57(20), 6315-6334.

Dolgui, A., Ivanov, D., Sethi, S. P., \& Sokolov, B. (2019a). Scheduling in production, supply chain and Industry 4.0 systems by optimal control. International Journal of Production Research, $57(2), 411-432$.

Dolgui, A., Ivanov, D., Potryasaev, S., Sokolov, B., Ivanova, M., \& Werner, F. (2019b). Blockchain-oriented dynamic modelling of smart contract design and execution control in the supply chain. International Journal of Production Research. https://doi.org/10.1080/ 00207543.2019.1627439.

Fragapane, G., Ivanov, D., Peron, M., Sgarbossa, F., \& Strandhagen, J. O. (2020). Increasing flexibility and productivity in industry 4.0 production networks with autonomous mobile robots and smart intralogistics. Annals of Operations Research. https://doi.org/10.1007/s10479-02003526-7.

Frazzon, E. M., Kück, M., \& Freitag, M. (2018). Data-driven production control for complex and dynamic manufacturing systems. CIRP Annals, 67, 515-518. https://doi.org/10.1016/ j.cirp.2018.04.033.

Helo, P., Phuong, D., \& Hao, Y. (2019). Cloud manufacturing-Scheduling as a service for sheet metal manufacturing. Computers and Operations Research, 110, 208-219.

Hwang, G., Lee, J., Park, J., \& Chang, T.-W. (2017). Developing performance measurement system for Internet of Things and smart factory environment. International Journal of Production Research, 55(9), 2590-2602.

Ivanov D. (2020) Predicting the impact of epidemic outbreaks on the global supply chains: A simulation-based analysis on the example of coronavirus (COVID-19 / SARS-CoV-2) case. Transportation research - Part E, 136., https://doi.org/10.1016/j.tre.2020.101922.

Ivanov D., Das A. (2020). Coronavirus (COVID-19 / SARS-CoV-2) and supply chain resilience: A research note. International journal of integrated supply management, forthcoming.

Ivanov, D., \& Dolgui, A. (2020). Viability of intertwined supply networks: Extending the supply chain resilience angles towards survivability. In A position paper motivated by COVID-19 outbreak. International Journal of Production: Research. https://doi.org/10.1080/ 00207543.2020.1750727. 
Ivanov, D., Sokolov, B., Dolgui, A., Werner, F., \& Ivanova, M. (2016). A dynamic model and an algorithm for short-term supply chain scheduling in the smart factory Industry 4.0. International Journal of Production Research, 54(2), 386-402.

Ivanov, D., Sethi, S., Dolgui, A., \& Sokolov, B. (2018). A survey on the control theory applications to operational systems, supply chain management and Industry 4.0. Annual Reviews in Control, 46, 134-147.

Ivanov, D., Sokolov, B., Chen, W., Dolgui, A., Werner, F., \& Potryasaev, S. (2020). A control approach to scheduling flexibly configurable jobs with dynamic structural-logical constraints. IISE Transactions. https://doi.org/10.1080/24725854.2020.1739787.

Kusiak, A. (2018). Smart manufacturing. International Journal of Production Research, 56(1-2), 508-517.

Leusin, M., Frazzon, E., Uriona Maldonado, M., Kück, M., \& Freitag, M. (2018). Solving the job-shop scheduling problem in the Industry 4.0 era. Technologies, 6(4), 107.

Liu, Y., Wang, L., Wang, X. V., Xu, X., \& Zhang, L. (2019). Scheduling in cloud manufacturing: State-of-the-art and research challenges. International Journal of Production Research, 57(1516), 4854-4879.

Mönch, L., Fowler, J. W., \& Mason, S. (2012). Production planning and control for semiconductor wafer fabrication facilities: Modeling, analysis, and systems. Dordrecht: Springer Science \& Business Media.

Mourtzis, D., \& Vlachou, E. (2018). A cloud-based cyber-physical system for adaptive shop-floor scheduling and condition-based maintenance. Journal of Manufacturing Systems, 47, 179-198.

$\mathrm{Ni}$, J. (2020). How China can rebuild global supply chain resilience after COVID-19. https:// www.weforum.org/agenda/2020/03/coronavirus-and-global-supply-chains/, accessed on April 4, 2020.

Nielsen, I., Dang, Q.-V., Bocewicz, G., \& Banaszak, Z. (2017). A methodology for implementation of Mobile robot in adaptive manufacturing environments. Journal of Intelligent Manufacturing, 28(5), 1171-1188.

Panetto, H., Iung, B., Ivanov, D., Weichhart, G., \& Wang, X. (2019). Challenges for the cyberphysical manufacturing enterprises of the future. Annual Reviews in Control, 47, 200-213.

Rossit, D. A., Tohmé, F., \& Frutos, M. (2019). Industry 4.0: Smart scheduling. International Journal of Production Research, 57(12), 3802-3813.

Shukla, N., Tiwari, M. K., \& Beydoun, G. (2019). Next generation smart manufacturing and service systems using big data analytics. Computers \& Industrial Engineering, 128, 905-910.

Siemens (2019). What doesn't happen keeps our world running smoothly - the power of MindSphere. https://www.plm.automation.siemens.com/global/en/topic/mindspherewhitepaper/28842 (accessed on November 18, 2019).

Tao, F., Qi, Q., Liu, A., \& Kusiak, A. (2018). Data-driven smart manufacturing. Journal of Manufacturing Systems, 48(C), 157-169.

Theorin, A., Bengtsson, K., Provost, J., Lieder, M., Johnsson, C., Lundholm, T., \& Lennartson, B. (2017). An event-driven manufacturing information system architecture for Industry 4.0. International Journal of Production Research, 55(5), 1297-1311.

Vahedi-Nouri, B., Tavakkoli-Moghaddam, R., \& Rohaninezhad, R. (2019). A multi-objective scheduling model for a cloud manufacturing system with pricing, equity, and order rejection. In D. Ivanov, A. Dolgui, \& F. Yalaoui (Eds.), Proceedings of the 9th IFAC Conference on Manufacturing Modeling, Management and Control MIM 2019, IFAC PapersOnLine (Vol. 52(13), pp. 2177-2182). Amsterdam: Elsevier.

Vespoli, S., Grassi, A., Guizzi, G., \& Santillo, L. C. (2019). Evaluating the advantages of a novel decentralised scheduling approach in the Industry 4.0 and cloud manufacturing era. In D. Ivanov, A. Dolgui, \& F. Yalaoui (Eds.), Proceedings of the 9th IFAC Conference on Manufacturing Modeling, Management and Control MIM 2019, IFAC PapersOnLine (Vol. 52(13), pp. 21702176). Amsterdam: Elsevier.

Xu, J., Tran, H. M., Gautam, N., \& Bukkapatnam, S. T. S. (2019). Joint production and maintenance operations in smart custom-manufacturing systems. IISE Transactions, 51(4), 406-421. 
Yang, H., Kumara, S., Bukkapatnam, S. T. S., \& Tsung, F. (2019). The internet of things for smart manufacturing: A review. IISE Transactions, 51(11), 1190-1216.

Yuan, M., Cai, X., Zhou, Z., Sun, C., Gu, W., \& Huang, J. (2019). Dynamic service resources scheduling method in cloud manufacturing environment. International Journal of Production Research. https://doi.org/10.1080/00207543.2019.1697000.

Zhang, J., Ding, G., Zou, Y., Qin, S., \& Fu, J. (2019). Review of job shop scheduling research and its new perspectives under Industry 4.0. Journal of Intelligent Manufacturing, 30(4), 1809-1830.

Zhou, L., Zhang, L., Sarker, B. R., Laili, Y., \& Ren, L. (2018). An event-triggered dynamic scheduling method for randomly arriving tasks in cloud manufacturing. International Journal of Computer Integrated Manufacturing, 31(3), 318-333. 